\title{
Post-locked down mental wellbeing among Malaysian adults: Factors of life satisfaction in urban Malaysia
}

\author{
Kususanto Ditto Prihadi ${ }^{1}$, Daryll Kurian ${ }^{2}$, Grace Jee Ern Nga ${ }^{2}$, Endah Kurniawati Purwaningtyas ${ }^{3}$ \\ ${ }^{1}$ Department of Psychology, Faculty of Social Science and Liberal Arts, UCSI University, Kuala Lumpur, Malaysia \\ ${ }^{2}$ Department of Psychology, Faculty of Behavioural Sciences, HELP University, Kuala Lumpur, Malaysia \\ ${ }^{3}$ Faculty of Psychology, Universitas Islam Negeri Malang, Malang, Indonesia
}

\begin{tabular}{l} 
Article Info \\
\hline Article history: \\
Received Jul 17, 2021 \\
Revised Nov 10, 2021 \\
Accepted Nov 23, 2021 \\
\hline
\end{tabular}

Keywords:

Life satisfaction

Lockdown

Mattering

Perceived social support

Spirituality

\begin{abstract}
Under the enforcement of the recovery movement control order (RMCO), citizens of Malaysia were allowed to commute for work with tight protocols of social distancing. In this period of time, most individuals were adjusting to the new norm after being locked down for about six weeks. With an assumption that the social dynamics could have been different from the prepandemic era, this study aims to investigate how mattering predicts life satisfaction among individuals who live in the urban area of western Malaysia in the aforementioned timeframe. The role of other variables, namely perceived social support (PSS), resilience, and spirituality was also investigated. Data was collected from 402 adults between 18 and 66 years of age $(M=25.44)$ who reside in the urban areas of Malaysia. A moderated serial mediation hypothesis was tested by employing the Bootstrap method in PROCESS Macro model 92. Our findings suggested that resilience does not play a significant role in the equation due to its insignificance in predicting life satisfaction after controlling the rest of the variables.
\end{abstract}

This is an open access article under the CC BY-SA license.

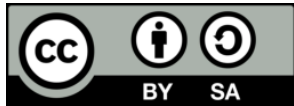

\section{Corresponding Author:}

Kususanto Ditto Prihadi

Department of Psychology, Faculty of Social Science and Liberal Arts, UCSI University

Taman Connaught, Cheras 56000, Kuala Lumpur, Malaysia

Email: pkditto@gmail.com

\section{INTRODUCTION}

In mid-June 2020, the government of Malaysia has ended the previously enforced lockdown or movement control order (MCO). The implication of MCO, albeit necessary to curb the virus infections, induced other phenomena, such as being away from loved ones, loneliness, misinformation on social media, financial insecurity and stigmatization [1]. Studies indicated that lockdown amidst the pandemic of coronavirus disease 2019 (COVID-19) was deteriorating to mental health [2]. In the context of Malaysia, the short notice of the enforcement of MCO deprived certain individuals of means of planning and preparation [3]. Moreover, the MCO was prolonged into six weeks, while it was initially planned to be two weeks. Longer quarantine duration, together with the fear of the virus itself, frustration, boredom, inadequate supplies, inadequate information, financial loss, and stigma pushed many individuals into posttraumatic stress, even when the lockdown policy was gradually loosened up [4].

In this time of adversity, it was evident that individuals who believe that they have adequate support from the people around them develop higher levels of resilience that enabled them to move on [5], [6]. In the context of post-lockdown Malaysia (Right after the first MCO, before the COVID infection cases spiked back up near the end of the year), people were allowed to gather in public places in limited numbers through social distancing, offices and educational institutions were gradually opened to accommodate their workers and students [7], [8]. This 'new normal' should have created a different social dynamic as to how the 
lockdown era did to the pre-pandemic era. This possible change in the dynamics of the social pattern led us to attempt in examining the formation of satisfaction with life (SWL) among urban adult Malaysians after the first lockdown amidst the pandemic was lifted.

Historically, SWL is a component of a larger construct, subjective well-being [9], but since Diener et al. [10] introduced the separated scale of SWL, it has been used extensively in many studies on SWL due to its correlations with measures of mental health and its predictive feature of future behaviour and attitude constructs such as suicide attempts, relationship satisfaction, and many others. In the context of our study, SWL is defined as how individuals in our research population perceived their life to be satisfying during the transition from the MCO to the new normal. Additionally, studies in the last decade of pre-pandemic indicated that SWL is significantly predicted by the sense that one matters to others [11]-[13].

By definition, mattering is a construct that measures how much we feel we matter to others [14]. Mattering was reported as a significant predictor of SWL before the pandemic [12], [15]. Consistently, a study on the formation of SWL during the lockdown in the Malaysian context reported that mattering was a robust significant predictor of SWL, partially mediated by perceived social inclusion among individuals with low and moderate levels of extraversion [16]. They also reported that the mediation did not occur among individuals with a high level of extraversion, whose levels of mattering robustly predicted the SWL. Another study in the same population and time frame suggested that the formation of SWL among locked-down young adults predicted by social comparison in social media, mediated by perceived social inclusion [17]. The robustness of mattering in predicting SWL can be justified by other studies in the Malaysian MCO context, mattering was reported as a significant predictor of other components of subjective well-being, such as unconditional self-acceptance [18], hedonic well-being [19], and perceived social inclusion [16], as well as a protective factor against depressive symptoms and suicide ideation [20]. Most of the Malaysian MCO context studies had reported that SWL and other components of subjective well-being are significantly predicted by mattering. Therefore, we hypothesized that mattering would significantly predict SWL among Malaysian urban adults during the post MCO 1.0.

Another study in the Malaysian context during the enforcement of MCO reported that perceived social support (PSS) and optimism partially, but significantly, explained the contribution of mattering on SWL among university students [21], and the significant role of PSS in predicting SWL has been consistently reported since the pre-pandemic era [22], [23]. Nevertheless, it was evident that individuals can only believe that they are socially supported when they have developed an adequate sense of mattering [24]-[26]. Individuals who believe that they matter to others also tend to believe that they are supported by others. Thus, the question lies in whether people who believe that they matter to others need to feel that others support them back in order to be satisfied with their lives.

In the post-pandemic, people are gradually getting back to offline social connectivity. Therefore, a different social dynamic might have taken place in this period, and it is essential to be studied. Moreover, mixed results were reported on whether offline social bonding is stronger than online social bonding in predicting PSS. A study among Korean young adults with gambling problems stated that offline bonding predicts stronger PSS than online bonding [27], while another study among individuals with HIV in China suggested the other way around [28]. In our context, the population was switching from the dominant reliance on digital communication into offline in the new normal. Therefore, we hypothesized that the significant connection between mattering and SWL occurred through a full mediation of PSS.

However, our further literature review indicated that SWL in the post-hardship situation was significantly predicted by resilience. For instance, in the post-war population of Baghdad, Iraq, in 2014, it was reported that resilience fully explained the link between PSS and personal growth and SWL [29]. Another example of the studies was that among young adults with severe disease of epilepsy, PSS lost its significance in predicting SWL after controlling for resilience [30]. In other words, in a post-hardship atmosphere, individuals require their social support to elevate their resilience, the ability to mentally or emotionally return to pre-crisis status quickly [31] before they can start to feel satisfied with their life again. Other studies reported that PSS is required to develop resilience not only in the post-hardship situation. It can build resilience even during times of hardships. For instance, Malaysian parents under the constant hardships of rising children with autism also reported that they consistent believe that they have the support from the people around them has kept them to believe that they can survive and move on stronger [32]. The similar phenomenon was also reported among Brazilians cancer patients [33], individuals with mental health issue [6] and locked-down adults amidst the pandemic in the USA [5]. Furthermore, other studies also reported that resilience predicted SWL among individuals without any experience of an extreme critical situation [34][36]. Additionally, mattering was also reported as a significant predictor of resilience, for example, studies among college students indicated that students with lower mattering tend to develop inadequate levels of resilience [37], [11]. Similar findings were also reported among elderlies [38], as well as on the general population during the COVID-19 pandemic [39]. 
Because this current study was conducted in Malaysia, we could not neglect the role of spirituality in explaining how most people perceive satisfying lives. First of all, 96\% of the citizens of Malaysia are attached to organized belief systems, namely Buddhism (19.8\%), Hinduism (6.3\%), Islam (61.3\%), and Christianity (9.2\%) [40], and every religious practice are freely conducted by each of their devotees [41], who considered their religion contributes a significant amount of thoughts and attitudes in life [42]. We included spirituality instead of religiosity in our study as the moderator variable because of the distinction between the two constructs. Religiosity is described as a structured framework of a particular set of beliefs and it refers to the compliance to religious organizations and engagement in their rituals [43]. Spirituality, on the other hand, refers to individual transcendental journey in finding purposes [44] and connection to others and individual version of the divine power of their belief [45]. Moreover, spirituality tends to be improved during such a lockdown [46], instead of religiosity, because many activities in the worshipping houses were not allowed by the government due to social distancing protocols. The next subsections will be our supporting references on the link between spirituality and the other variables.

Greater spirituality had been reported to predict greater subjective happiness and SWL [47]. In line with that, Alorani and Alradayeh [48] reported a positive, significant and prevalent $(\mathrm{r}-\mathrm{sq}=.53)$ correlation between spirituality and SWL among university students in Jordan. It is also important to notice that individuals with low levels of spirituality tend to develop lower levels of SWL [49] because spirituality is one of the most significant factors that help individuals cope with stressful situations [50], even among individuals with mental illness [51]. In other words, we hypothesized that spirituality played a conditional (moderation) role in the link between SWL and any of its predictors, where the positive links tend to be the strongest among individuals with higher spirituality because it interacts with how individuals value and identify their roles in the society [52].

Defined as having a deep connection with self, divine being, and others, spirituality helps one to identify and share the feelings of others [53], [54]. In line with that, Miguel-Rojas et al. [55] suggested that spirituality is positively correlated with a positive understanding that others have sympathy and empathy towards oneself, which led to the sense of receiving support from others. Consistent with that, our previous study in the Malaysian context before the MCO suggested that spirituality significantly predicts one of the preconditions of PSS, which is emotional intelligence [56] and some previous studies also confirmed that spirituality predicts another precondition, social-connectedness [53], [54]. Accordingly, various studies from various settings reported a positive link between spirituality and PSS, such as among university students in Jordan [48], women with preeclampsia [57], burn survivors in Iran [58], African American women with breast cancer [59].

In the same light as the previous paragraph, Gerson [60] reported that spirituality predicted PSS, resilience, and life satisfaction and added that spirituality was a more robust predictor of resilience than PSS, which required positive emotions to mediate its contribution on resilience. Confirming that, Dey et al. [61] advocated that a greater level of spirituality predicted greater resilience, which explains the further link to greater levels of life satisfaction and positive affect. Almost similarly, studies on resilience in nations with recent war history disclosed that spirituality predicted resilience through the decreased aggressive behaviour [62]. Higher spirituality tends to contribute to higher resilience levels among adolescents [45], individuals with abuse history [44], facing midlife crisis [63], and the general population [64], [65].

The aforementioned studies suggested that spirituality would moderate all the paths between mattering to SWL, directly or indirectly. This led us to our moderated serial mediation hypothesis, as illustrated in Figure 1. The hypothesized model in Figure 1 was our attempt to conceptualize the theoretical framework discussed in the previous paragraphs.

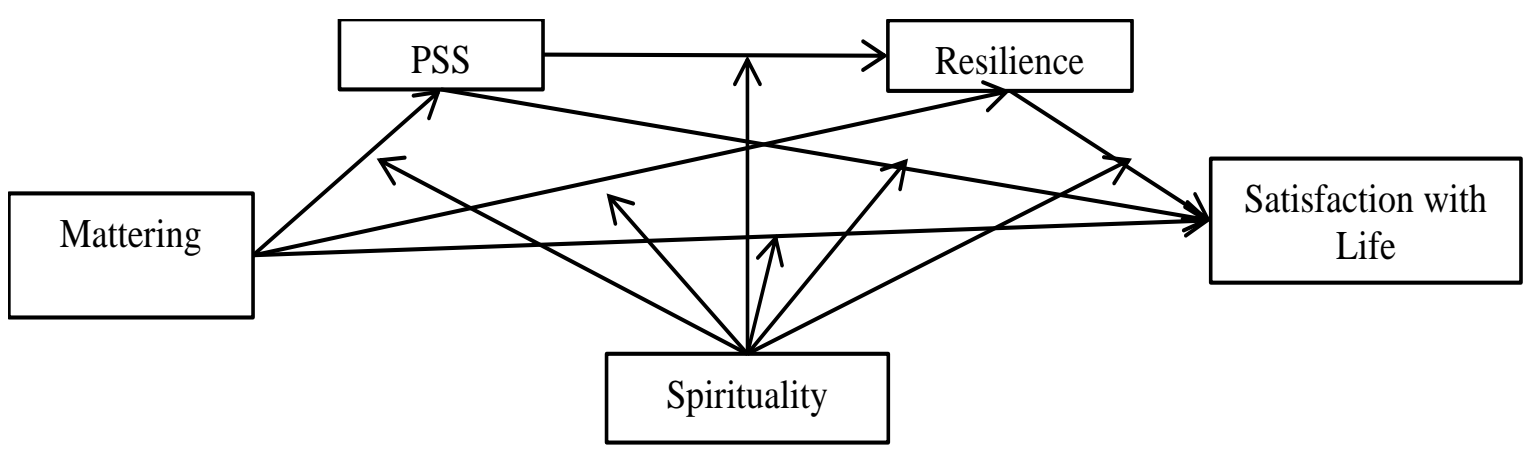

Figure 1. Moderated serial mediation hypothesis 


\section{RESEARCH METHOD}

The proposal of this current study has been approved by the ethic review board of the Department of Psychology, HELP University (ERB: E202011-S003). Several adjustments, such as back translation of the scales and modifications of the informed consent form were conducted based on their suggestions. Four hundred and two adults between 18-66 years old reside in Kuala Lumpur and Selangor states during the postMCO 1.0 period were randomly recruited by using social media. They had given their informed consent before taking part in data collection by giving their approval remark in the google form, without their approval, items of the scales would not be accessible. Each participant was compensated with an e-wallet credit of 5 Malaysian Ringgit, and there is no conflict of interest between the investigators and the participants. The participants were asked to submit their informed consent and responses to the aforementioned scales through online forms.

SWL was measured by the participant's mean score on the bilingual Life Satisfaction Inventory [10], with the internal reliability is $\alpha=.87$ [10]. Mattering was measured using the general mattering scale (GMS) [66], with the internal reliability of the scale ranges from .89. Perceived social support was assessed with multidimensional scale of perceived social support (MSPSS) [67], the internal reliability is $\alpha=.92$. Resilience was assessed using the Brief Resilience Scale [68] with the Cronbach Alpha was $\alpha=.91$. Spirituality is measured through the total score obtained from the Spirituality Assessment Scale [69], with the Cronbach Alpha was $\alpha=.87$.

\section{RESULTS}

\subsection{Assumption tests}

Saphiro-Wilk test was conducted in order to test the normality of the distribution of the data, and as shown in Table 1, we discovered that none of our data is normally distributed $(\mathrm{p}<00)$. This result is expected because the data was collected after a prolonged lockdown, where individuals tend to perceive higher levels of resilience for surviving the lockdown, as well as higher PSS for the same reason. Table 2 indicated that there is no multicollinearity among our variables as variance inflation factors (VIF) and tolerance $(=1 / \mathrm{VIF})$ of all predictors in the current study were below values of 2.00 and 1.00 , respectively.

Table 1 . Tests of normality

\begin{tabular}{lccc}
\hline & \multicolumn{3}{c}{ Shapiro-Wilk } \\
& Statistic & df & Sig. \\
\hline Mat & .974 & 405 & .000 \\
PSS & .950 & 405 & .000 \\
Res & .904 & 405 & .000 \\
Spir & .957 & 405 & .000 \\
LifSat & .984 & 405 & .000 \\
\hline
\end{tabular}

Table 2. Collinearity diagnostics $(a)$

\begin{tabular}{ccccccccc}
\hline \multirow{2}{*}{ Model } & \multirow{2}{*}{ Dimension } & \multirow{2}{*}{ Eigenvalue } & \multirow{2}{*}{ Condition index } & \multicolumn{4}{c}{ Variance proportions } \\
& & & & (Constant) & Mat & PSS & Res & Spir \\
\hline 1 & 1 & 4.844 & 1.000 & .00 & .00 & .00 & .00 & .00 \\
& 2 & .075 & 8.043 & .01 & .05 & .01 & .02 & .97 \\
& 3 & .045 & 10.394 & .05 & .61 & .01 & .18 & .00 \\
& 4 & .024 & 14.188 & .00 & .33 & .77 & .18 & .02 \\
& 5 & .012 & 19.878 & .93 & .00 & .21 & .63 & .00 \\
\hline
\end{tabular}

* $a$ dependent variable: LifSat

The absence of multicolinearity depicted in Table 2 indicates that the hypothesized model is fit because there is no correlation among the predicting variables (mattering, PSS, resilience, and spirituality). In other words, these variables do not explain the same variance in SWL, therefore, their statistical significance would not be reduced by overlapping prediction. The aforementioned assumption tests confirmed our choice in utilizing bootstrap method due to its robustness in analyzing non-normally distributed data. We chose to have 10,000 sampling and $95 \%$ confidence interval for our bootstrapping to gain a better screenshot of ech path. Figure 2 illustrates the results of the path analyses that have been conducted through the bootstrapping method with 10,000 sampling and 95\% confidence intervals by utilizing PROCESS Macro Model 92 for SPSS. 


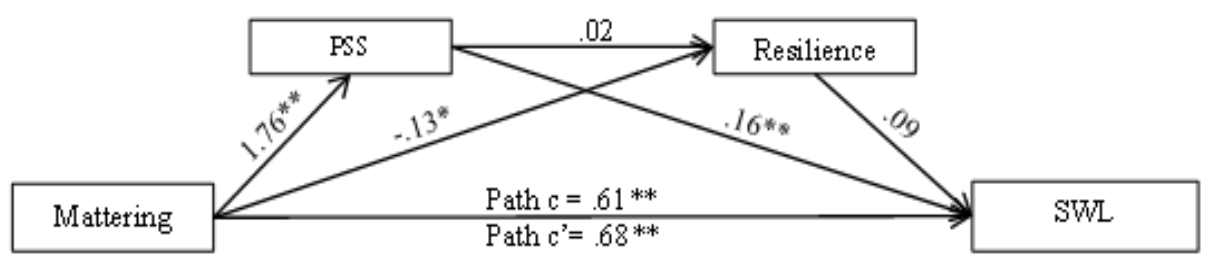

Figure 2. Results of the path analysis of the serial mediation model

As illustrated in Figure 2, all of the paths are significant except for the path $\mathrm{d}_{21}$ (PSS to resilience) and $b_{2}$ (resilience to SWL). In other words, PSS did not significantly predict resilience, and resilience did not significantly predict SWL. The insignificance of these two paths confirmed that resilience did not play any significant mediating role in the link between mattering and SWL neither did it in the moderated serial mediation model. Additionally, the mediation of PSS can be seen as partial, despite significant, because path c' was significant, which means that after controlling for PSS, mattering was still considered a significant predictor of SWL. Table 3 depictes that the direct effect of mattering on SWL was significant at all levels of spirituality, which means that spirituality did not interact significantly with mattering in predicting SWL.

Table 3. Conditional indirect effects

\begin{tabular}{cccccc}
\hline \multicolumn{1}{c}{ Indirect effect } & Spirituality & Effect & BootSE & BootLLCI & BootULCI \\
\hline Mat $\rightarrow$ PSS $\rightarrow$ SWL & 26.96 & .18 & .06 & .06 & .30 \\
& 41.00 & .21 & .04 & .13 & .29 \\
& 54.00 & .22 & .06 & .12 & .36 \\
$\mathrm{Mat} \rightarrow \mathrm{ReS} \rightarrow \mathrm{SWL}$ & 26.96 & .01 & .01 & -.01 & .04 \\
& 41.00 & .01 & .01 & -.01 & .03 \\
$\mathrm{Mat} \rightarrow \mathrm{PSS} \rightarrow \mathrm{ReS} \rightarrow \mathrm{SWL}$ & 54.00 & -.00 & .02 & -.05 & .04 \\
& 26.96 & .01 & .01 & -.00 & .04 \\
& 41.00 & -.00 & .00 & -.01 & .01 \\
& 54.00 & .00 & .01 & -.02 & .02 \\
\hline
\end{tabular}

\section{DISCUSSION}

The findings suggested that the PSS partially mediated the link between mattering and SWL. Every path of this model was consistent with the previous findings. The significance of mattering in predicting SWL had been reported by previous studies since before the pandemic [12], [15], as well as our findings that mattering predicts PSS [24]-[26]. Another study during the lockdown in Malaysia also yielded the same findings that PSS partially mediated the link between mattering and SWL [21]. The similarity of the results across the time indicated that the significance of mattering in predicting SWL was not affected by the social dynamic changes, such as lockdown or elevated inclination towards social media.

Nevertheless, no similar situation can be reported on resilience; our findings suggested that resilience seemed did not play any significant role in the equation. It was inconsistent with the report that PSS significantly predicted it [29], [30], [32] and that it predicted SWL [34]-[36]. It could be explained that our participants might not see themselves as being resilient as the data was not collected during the hardship or that the six weeks of lockdown was not considered stressful enough to feel that they required extraordinary resilience in order to move on with their lives.

Our results also suggested that none of the conditional indirect effects was significant; in other words, spirituality did not have any moderation effect in the proposed model. While spirituality might predict SWL [49]-[51], it did not show any significant interaction with the other variables. This phenomenon indicated that spirituality in our participants was not social-based; they being spiritual and non-spiritual was not affected by their mattering or PSS, because online social feedback relating to spirituality might have been less prevalent compared to the offline social feedback in ritual activities in worshipping houses and social gathering as studied previously [53], [58].

\subsection{Limitation}

Our study was not without limitations. First of all, we did not take into account the individual degree of adjustment people needs to make based on their profession. Different professions might require different degrees of adjustment when practised from home, and therefore they might produce different social dynamics; in other words, the degree of adjustment to work from home (WFH) might play a moderation role 
in the equation. The second methodological limitation is that we did not take into account of the separation between intrinsic and extrinsic spirituality, as suggested in the study of $\mathrm{Ng}$ and Prihadi [56]. It was questionable that our findings were not consistent with the recent studies that spirituality predicted SWL [50], PSS [56] and resilience [45]. The only possible explanation we can obtain is that spirituality levels of our participants were predominantly extrinsic or social-driven, and when the social religious activities were absent due to the lockdown, their spirituality score tend to be declined. It is suggested for future studies to focus merely on the intrinsic spirituality in order to isolate individuals' spirituality from the influence of their social aspects of spirituality.

\section{CONCLUSION}

Every aspect of the study has been discussed thoroughly, including the limitations of our studies and the suggestion for future studies. It is important to note that the findings of our studies have confirmed the robustness and significance of mattering in predicting PSS, resilience, and SWL. Thus, it is expected that future studies in social contexts paying more attention to this particular variable.

Knowing that mattering holds significance in predicting SWL, and that SWL holds importance in so many psychological constructs. It is suggested for authorities and employers to implement codes of conduct/ethics that promote mattering by taking into account of the positives effect that it could bring.

\section{ACKNOWLEDGEMENTS}

Publication of this study is funded by the Internal Research Grant from UCSI University, Malaysia.

\section{REFERENCES}

[1] S. Sood, "Psychological effects of the coronavirus disease-2019 pandemic," Research \& Humanities in Medical Education, vol. 7, no. 11 , pp. 23-26, 2020.

[2] S. Casale and G. L. Flett, "Interpersonally-based fears during the COVID-19 pandemic: Reflections on the fear of missing out and the fear of not mattering constructs," Clinical Neuropsychiatry, vol. 17, no. 2, pp. 88-93, 2020, doi: 10.36131/CN20200211.

[3] M. T. Johnson, E. A. Johnson, L. Webber, and D. Nettle, "Mitigating social and economic sources of trauma: The need for universal basic income during the coronavirus pandemic.," Psychological Trauma: Theory, Research, Practice, and Policy, vol. 12, no. S1, pp. S191--S192, Aug. 2020, doi: 10.1037/tra0000739.

[4] S. K. Brooks et al., "The psychological impact of quarantine and how to reduce it: rapid review of the evidence," The Lancet, vol. 395, no. 10227, pp. 912-920, Mar. 2020, doi: 10.1016/S0140-6736(20)30460-8.

[5] W. D. S. Killgore, E. C. Taylor, S. A. Cloonan, and N. S. Dailey, "Psychological resilience during the COVID-19 lockdown," Psychiatry Research, vol. 291, p. 113216, Sep. 2020, doi: 10.1016/j.psychres.2020.113216.

[6] E. Koelmel, A. J. Hughes, K. N. Alschuler, and D. M. Ehde, "Resilience mediates the longitudinal relationships between social support and mental health outcomes in multiple sclerosis," Archives of Physical Medicine and Rehabilitation, vol. 98, no. 6, pp. 1139-1148, Jun. 2017, doi: 10.1016/j.apmr.2016.09.127.

[7] J. H. Hashim, M. A. Adman, Z. Hashim, M. F. Mohd Radi, and S. C. Kwan, "COVID-19 epidemic in Malaysia: epidemic progression, challenges, and response," Frontiers in Public Health, vol. 9, p. 560592, May 2021, doi: 10.3389/fpubh.2021.560592.

[8] Ministry of Health Malaysia, "COVID-19 Malaysian Ministry of Health Guidelines (In Malaysia: COVID-19 Garis Panduan Kementerian Kesihatan Malaysia).” 2020, Accessed: May 03, 2020. [Online]. Available: https://moh.gov.my/index.php/pages/view/2019-ncov-wuhan-guidelines.

[9] W. Pavot and E. Diener, "The satisfaction with life scale and the emerging construct of life satisfaction," Journal of Positive Psychology, vol. 3, no. 2, pp. 137-152, Apr. 2008, doi: 10.1080/17439760701756946.

[10] E. Diener, R. A. Emmons, R. J. Larsem, and S. Griffin, “The satisfaction with life scale," Journal of Personality Assessment, vol. 49, no. 1, pp. 71-75, Feb. 1985, doi: 10.1207/s15327752jpa4901_13.

[11] G. Flett, A. Khan, and C. Su, "Mattering and psychological well-being in college and university students: review and recommendations for campus-based initiatives," International Journal of Mental Health and Addiction, vol. 17, no. 3, pp. 667680, Apr. 2019, doi: 10.1007/s11469-019-00073-6.

[12] A. Froidevaux, A. Hirschi, and M. Wang, "The role of mattering as an overlooked key challenge in retirement planning and adjustment," Journal of Vocational Behavior, vol. 94, pp. 57-69, Jun. 2016, doi: 10.1016/j.jvb.2016.02.016.

[13] A. K. Jung and M. J. Heppner, "Development and Validation of a Work Mattering Scale (WMS)," Journal of Career Assessment, vol. 25, no. 3, pp. 467-483, Aug. 2017, doi: 10.1177/1069072715599412.

[14] G. L. Flett, The psychology of mattering: Understanding the human need to be significant. Massachusetts: Academic Press, 2018.

[15] F. E. Markowitz, S. M. Kintzle, C. A. Castro, and S. L. Lancaster, "Effects of perceived public regard on the well-being of military veterans," Society and Mental Health, vol. 10, no. 3, pp. 291-304, Nov. 2020, doi: 10.1177/2156869319894372.

[16] K. D. Prihadi, E. S. Z. Lim, E. Sim, and K. Y. Chong, "Mattering and life satisfaction among the quarantined adults in Malaysia during the COVID-19 pandemic," International Journal of Public Health Science (IJPHS), vol. 10, no. 1, pp. 189-193, Mar. 2021, doi: 10.11591/ijphs.v10i1.20684.

[17] P. P. T. Sim and K. Prihadi, "Social comparison and life satisfaction in social media: The role of mattering and state self-esteem," International Journal of Public Health Science (IJPHS), vol. 9, no. 3, pp. 245-254, Sep. 2020, doi: 10.11591/ijphs.v9i3.20509.

[18] S.-Y. Kam and K. D. Prihadi, "Why students tend to compare themselves with each other? The role of mattering and unconditional self-acceptance," International Journal of Evaluation and Research in Education (IJERE), vol. 10, no. 2, pp. 441447, Jun. 2021, doi: 10.11591/ijere.v10i2.21238.

[19] H. Taniguchi, "Interpersonal mattering in friendship as a predictor of happiness in Japan: The case of tokyoites," Journal of Happiness Studies, vol. 16, no. 6, pp. 1475-1491, Aug. 2015, doi: 10.1007/s10902-014-9570-z. 
[20] K. D. Prihadi, C. Y. S. Wong, E. Y. V Chong, and K. Y. X. Chong, "Suicidal thoughts among university students: The role of mattering, state self-esteem and depression level," International Journal of Evaluation and Research in Education (IJERE), vol. 9, no. 3, pp. 494-502, Sep. 2020, doi: 10.11591/ijere.v9i3.20587.

[21] Z. Foo and K. D. Prihadi, "Happiness of university students in new normal Malaysia: The role of mattering, optimism, and social support," International Journal of Evaluation and Research in Education (IJERE), vol. 10, no. 2, p. 448, Jun. 2021, doi: 10.11591/ijere.v10i2.21138.

[22] H. J. Oh, E. Ozkaya, and R. Larose, "How does online social networking enhance life satisfaction? the relationships among online supportive interaction, affect, perceived social support, sense of community, and life satisfaction," Computers in Human Behavior, vol. 30, pp. 69-78, Jan. 2014, doi: 10.1016/j.chb.2013.07.053.

[23] T. Oshio, H. Kimura, T. Nishizaki, and T. Omori, "Association between the use of social networking sites, perceived social support, and life satisfaction: Evidence from a population-based survey in Japan," PLOS ONE, vol. 15, no. 12, p. e0244199, Dec. 2020, doi: 10.1371/journal.pone.0244199.

[24] S. A. Brandt and C. L. Carmichael, "Does online support matter? The relationship between online identity-related support, mattering, and well-being in sexual minority men," Computers in Human Behavior, vol. 111, p. 106429, Oct. 2020, doi: 10.1016/j.chb.2020.106429.

[25] J. Haizlip, C. McCluney, M. Hernandez, B. Quatrara, and V. Brashers, "Mattering: How Organizations, Patients, and Peers Can Affect Nurse Burnout and Engagement," Journal of Nursing Administration, vol. 50, no. 5, pp. 267-273, May 2020, doi: 10.1097/NNA.0000000000000882.

[26] Q. Y. Xu, S. F. Li, and L. Yang, "Perceived social support and mental health for college students in mainland China: the mediating effects of self-concept," Psychology, Health and Medicine, vol. 24, no. 5, pp. 595-604, May 2019, doi: 10.1080/13548506.2018.1549744.

[27] s. lee, j. e. chung, and n. park, "network Environments and Well-Being: An Examination of Personal Network Structure, Social capital, and perceived social support," Health Communication, vol. 33, no. 1, pp. 22-31, 2016.

[28] X. Han, B. Li, J. Qu, and Q. Zhu, "Weibo friends with benefits for people live with HIV/AIDS? The implications of Weibo use for enacted social support, perceived social support and health outcomes," Social Science and Medicine, vol. 211, pp. 157-163, Aug. 2018, doi: 10.1016/j.socscimed.2018.06.016.

[29] H. K. Mahdi, K. Prihadi, and S. Hashim, "Posttraumatic growth and resilience after a prolonged war: a study in Baghdad, Iraq," International Journal of Evaluation and Research in Education (IJERE), vol. 3, no. 3, pp. 197-204, Sep. 2014, doi: 10.11591/ijere.v3i3.6316.

[30] E. Moser, F. Chan, N. L. Berven, J. Bezyak, K. Iwanaga, and E. Umucu, "Resilience and life satisfaction in young adults with epilepsy: The role of person-environment contextual factors," Journal of Vocational Rehabilitation, vol. 52, no. 2, pp. 157-171, Mar. 2020, doi: 10.3233/jvr-191067.

[31] I. De Terte and C. Stephens, "Psychological resilience of workers in high-risk occupations," Stress and Health, vol. 30, no. 5, pp. 353-355, Dec. 2014, doi: 10.1002/smi.2627.

[32] H. Arnous and K. J. Yeo, "Mediating effect of perceived social support in the relationship between resilience and self-esteem among parents of children with autism spectrum disorder," in Proceedings of the 5th Universitas Ahmad Dahlan Public Health Conference (UPHEC 2019), 2020, pp. 312-319, doi: 10.2991/ahsr.k.200311.059.

[33] A. L. S. Costa, M. M. Heitkemper, G. P. Alencar, L. P. Damiani, R. M. Da Silva, and M. E. Jarrett, "Social support is a predictor of lower stress and higher quality of life and resilience in brazilian patients with colorectal cancer," Cancer Nursing, vol. 40, no. 5, pp. 352-360, Sep. 2017, doi: 10.1097/NCC.0000000000000388.

[34] G. Kılınç, E. Yıldız, and F. Kavak, "The relationship between psychological resilience and life satisfaction in copd patients," Journal of Psychiatric Nursing, vol. 10, no. 2, pp. 111-116, 2019, doi: 10.14744/phd.2019.60362.

[35] S. Santilli, S. Grossen, and L. Nota, "Career adaptability, resilience, and life satisfaction among Italian and Belgian Middle school students," Career Development Quarterly, vol. 68, no. 3, pp. 194-207, Sep. 2020, doi: 10.1002/cdq.12231.

[36] Z. T. Temiz and I. T. Comert, "The relationship between life satisfaction, attachment styles, and psychological resilience in university students," Dusunen Adam The Journal of Psychiatry and Neurological Sciences, vol. 31, no. 3, pp. 274-283, 2018, doi: 10.5350/DAJPN2018310305.

[37] G. L. Flett and T. Nepon, "Mattering versus self-esteem in university students: associations with regulatory focus, social feedback, and psychological distress," Journal of Psychoeducational Assessment, vol. 38, no. 6, pp. 663-674, Sep. 2020, doi: $10.1177 / 0734282919890786$.

[38] G. L. Flett and M. J. Heisel, "Aging and feeling valued versus expendable during the covid-19 pandemic and beyond: a review and commentary of why mattering is fundamental to the health and well-being of older adults," International Journal of Mental Health and Addiction, pp. 1-27, Jun. 2020, doi: 10.1007/s11469-020-00339-4.

[39] G. L. Flett and M. Zangeneh, "Mattering as a vital support for people during the COVID-19 pandemic: The benefits of feeling and knowing that someone cares during times of crisis," Journal of Concurrent Disorders, vol. 2, no. 1, pp. 106-123, 2020.

[40] D. of S. Malaysia, "Population and housing census, Malaysia $2010 \quad$ (2010 Census)." 2012. http://www/statistics.gov.my/portal/portal/index.php? (accessed Feb 19, 2021).

[41] I. Abubakar, "The religious tolerance in Malaysia: An Exposition," Advances in Natural and Applied Sciences, vol. 7, no. 1, pp. 90-97, 2013.

[42] C. L. Park and J. M. Slattery, Spirituality, Emotions, and Physical Health. New York: Oxford University Press, 2012

[43] H. Koenig, D. King, and V. B. Carson, Handbook of religion and health. New York: Oxford University Press, 2012.

[44] L. B. Smith, A. S. Lenz, and D. Strohmer, "Differential prediction of resilience among individuals with and without a history of abuse," Counseling and Values, vol. 62, no. 1, pp. 106-122, Apr. 2017, doi: 10.1002/cvj.12052.

[45] G. Shahina and A. Parveen, "Role of spirituality in building up resilience and mental health among adolescents," Indian Journal of Positive Psychology, vol. 11, no. 4, pp. 392-397, 2020.

[46] J. E. Refle et al., "First results of the Swiss Household Panel - COVID-19 Study," FORS Working Paper Series, paper 2020-1, pp. 1-51, 2020.

[47] I. D. Gaur, "Issues of canons and cultures," Cultural Studies in India, p. 139, 2017.

[48] O. I. Alorani and M. F. Alradaydeh, "Spiritual well-being, perceived social support, and life satisfaction among university students," International Journal of Adolescence and Youth, vol. 23, no. 3, pp. 291-298, Jul. 2018, doi: 10.1080/02673843.2017.1352522.

[49] F. Kasapoğlu and A. Yabanigül, "Marital Satisfaction and Life Satisfaction: The Mediating Effect of Spirituality," Spiritual Psychology and Counseling, vol. 3, no. 2, pp. 177-195, 2018, doi: 10.37898/spc.2018.3.2.0048.

[50] R. F. Carranza Esteban, J. E. Turpo-Chaparro, O. Mamani-Benito, J. H. Torres, and F. S. Arenaza, "Spirituality and religiousness

Int J Public Health Sci, Vol. 11, No. 1, March 2022: 294-302 
as predictors of life satisfaction among Peruvian citizens during the COVID-19 pandemic," Heliyon, vol. 7, no. 5, p. e06939, May 2021, doi: 10.1016/j.heliyon.2021.e06939.

[51] K. Maier and J. Surzykiewicz, "Mediated association between spirituality and life satisfaction in chronically Ill undergraduate students," Psychology of Religion and Spirituality, vol. 12, no. 3, pp. 311-323, Aug. 2020, doi: 10.1037/rel0000275.

[52] A. Vishkin, Y. E. Bigman, R. Porat, N. Solak, E. Halperin, and M. Tamir, "God rest our hearts: Religiosity and cognitive reappraisal," Emotion, vol. 16, no. 2, pp. 252-262, Mar. 2016, doi: 10.1037/emo0000108.

[53] A. Apostolides, "Empathy and imagination: Nurturing children's and adolescent's spiritual well-being in the digital environment," STJ $\mid$ Stellenbosch Theological Journal, vol. 4, no. 1, pp. 73-89, Jun. 2018, doi: 10.17570/stj.2018.v4n1.a04.

[54] M. De Souza, "The empathetic mind: The essence of human spirituality," International Journal of Children's Spirituality, vol. 19, no. 1, pp. 45-54, Jan. 2014, doi: 10.1080/1364436X.2014.897221.

[55] and, J. Miguel-Rojas, E. Vílchez-Quevedo, and M. Reyes-Bossio, "Espiritualidad e Inteligencia Emocional en estudiantes universitarios de la ciudad de Ayacucho," Interacciones: Revista de Avances en Psicología, vol. 4, no. 2, pp. 131-141, May 2018, doi: $10.24016 / 2018 . v 4 n 2.104$

[56] H. W. Ng and K. Prihadi, "Why some religious individuals are not emotionally smart? The explanatory role of spirituality," International Journal of Evaluation and Research in Education, vol. 9, no. 1, pp. 83-92, Mar. 2020, doi: 10.11591/ijere.v9i1.20455.

[57] M. and Akbarzadeh and F. Ahmadinezhad, "Investigating the relationship of spiritual wellbeing with perceived stress and perceived social support among women with preeclampsia," Health, Spirituality and Medical Ethics, vol. 6, no. 4, pp. 2-9, Dec. 2019, doi: 10.29252/jhsme.6.4.2.

[58] F. Ajoudani, H. Jafarizadeh, and J. Kazamzadeh, "Social support and posttraumatic growth in Iranian burn survivors: The mediating role of spirituality," Burns, vol. 45, no. 3, pp. 732-740, May 2019, doi: 10.1016/j.burns.2018.10.013.

[59] T. Thompson, M. Pérez, M. Kreuter, J. Margenthaler, G. Colditz, and D. B. Jeffe, "Perceived social support in African American breast cancer patients: Predictors and effects," Social Science and Medicine, vol. 192, pp. 134-142, Nov. 2017, doi: 10.1016/j.socscimed.2017.09.035.

[60] M. W. Gerson, "Spirituality, social support, pride, and contentment as differential predictors of resilience and life satisfaction in emerging adulthood," Psychology, vol. 09, no. 03, pp. 485-517, 2018, doi: 10.4236/psych.2018.93030.

[61] N. E. Y. Dey, B. Amponsah, and C. B. Wiafe-Akenteng, "Spirituality and subjective well-being of Ghanaian parents of children with special needs: The mediating role of resilience," Journal of Health Psychology, vol. 26, no. 9, pp. 1377-1388, Aug. 2021, doi: $10.1177 / 1359105319873956$.

[62] Y. Sadeghifard, Y. Veisani, F. Mohamadian, A. Azizifar, S. Naghipour, and S. Aibod, "Relationship between aggression and individual resilience with the mediating role of spirituality in academic students - A path analysis," Journal of Education and Health Promotion, vol. 9, no. 1, p. 2, 2020, doi: 10.4103/jehp.jehp_324_19.

[63] Y. K. Le, R. L. Piedmont, and T. A. Wilkins, "Spirituality, religiousness, personality as predictors of stress and resilience among middle-aged Vietnamese-Born American Catholics," Mental Health, Religion and Culture, vol. 22, no. 7, pp. 754-768, Aug. 2019, doi: 10.1080/13674676.2019.1646235.

[64] B. W. Smith, J. A. Ortiz, K. T. Wiggins, J. F. Bernard, and J. Dalen, Spirituality, resilience, and positive emotions., no. August 2016. New York: Oxford University Press, 2012.

[65] P. Van Cappellen, M. Toth-Gauthier, V. Saroglou, and B. L. Fredrickson, "Religion and well-being: the mediating role of positive emotions," Journal of Happiness Studies, vol. 17, no. 2, pp. 485-505, Apr. 2016, doi: 10.1007/s10902-014-9605-5.

[66] M. Rosenberg and B. C. McCullough, "Mattering: Inferred significance and mental health among adolescents," Research in Community \& Mental Health, vol. 2, pp. 163-182, 1981.

[67] G. D. Zimet, N. W. Dahlem, S. G. Zimet, and G. K. Farley, "The multidimensional scale of perceived social support," Journal of Personality Assessment, vol. 52, no. 1, pp. 30-41, 1988, doi: 10.1207/s15327752jpa5201_2.

[68] B. W. Smith, J. Dalen, K. Wiggins, E. Tooley, P. Christopher, and J. Bernard, "The brief resilience scale: Assessing the ability to bounce back," International Journal of Behavioral Medicine, vol. 15, no. 3, pp. 194-200, Sep. 2008, doi: 10.1080/10705500802222972.

[69] J. W. Howden, "Development and psychometric characteristics of the spirituality assessment scale," Thesis, Texas Woman's University, 1992.

\section{BIOGRAPHIES OF AUTHORS}

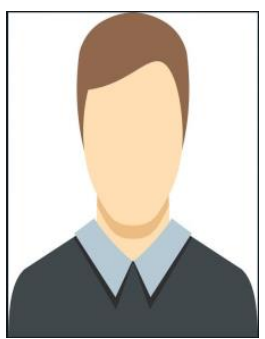

Kususanto Ditto Prihadi (iD /8d SC P Head of Research and Postgraduate Studies in the Faculty of Social Science and Liberal Arts, UCSI University Malaysia. His main research interest is the psychology of mattering and self. Most of his papers in the last two years were related to role of mattering on mental health and people's wellbeing. He can be reached at email: fosslaresearch@gmail.com

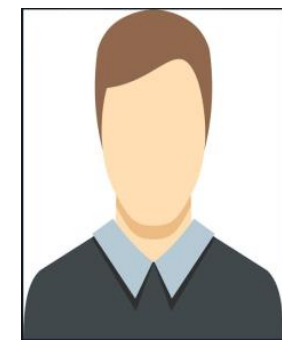

Daryll Kurian (ID 8I SC P He is the vice president of Psi-Chi honors society, an international organization of psychology students with CGPA not less than 3.5 all over the world. As an exploring psychology student of the department of Psychology, Faculty of Behavioral Science, HELP University Malaysia, he keeps himself open to any are of research in psychology; his first two researches were on the wellbeing during the COVID outbreak. He can be reached at email: fosslaresearch@gmail.com. 

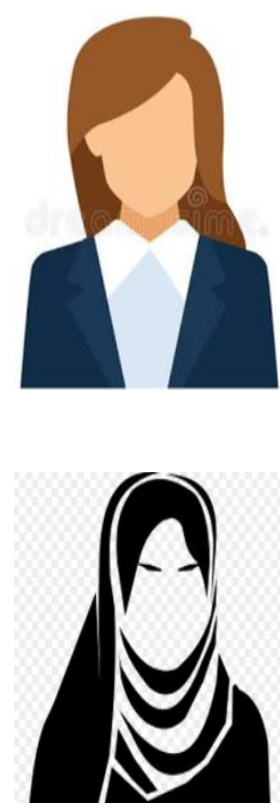

Grace Jee Ern Nga (D) 81 SC P A Malaysian national who studies psychology in the department of Psychology, Faculty of Behavioral Science, HELP University Malaysia with deep interest in practicing her skills in special needs education. Despite her first two published papers are on the effect of COVID lockdown on people's wellbeing, her major research is on the special needs education. She is working closely with one of the best special needs education practitionist in Malaysia, Melissa Jane Chua from HELP University Malaysia. She can be reached at email: fosslaresearch@gmail.com.

Endah Kurniawati Purwaningtyas (iD 8) SC P An Indonesian lecturer who holds doctorate in Industrial and Organizational Psychology with intensive research interest at Psychology of leadership and performance. Most of her research papers in the last three years are related to Islamic Leadership, Servant Leadership at higher education and performance. She is currently the vice dean of student affairs and partnership in the Psychology Faculty, UIN Maulana Malik Ibrahim Malang, Indonesia. She can be reached at email: fosslaresearch@ gmail.com. 